\title{
Galectin-3 expression favors metastasis in murine melanoma
}

\author{
Andréia Neves Comodo ${ }^{1}$, Andre Luis Lacerda Bachi ${ }^{2}$, Maria Fernanda Soares ${ }^{1}$, Marcello Franco ${ }^{1}$, \\ Vicente de Paulo Castro Teixeira ${ }^{1}$
}

${ }^{1}$ Departamento de Patologia, Universidade Federal de São Paulo, São Paulo, Brasil

${ }^{2}$ Departamento de Microbiologia, Imunologia e Parasitologia, Universidade Federal de São Paulo, São Paulo, Brasil

Email: vicente.teixeira@unifesp.br

Received 23 July 2013; revised 24 August 2013; accepted 16 September 2013

Copyright (C) 2013 Andréia Neves Comodo et al. This is an open access article distributed under the Creative Commons Attribution License, which permits unrestricted use, distribution, and reproduction in any medium, provided the original work is properly cited.

\begin{abstract}
Galectin-3 is a member of the lectin family that binds $\beta$-galactosides and plays an important role in several types of tumors. Melanoma is an invasive cancer responsible for $80 \%$ of deaths associated to skin cancers. There are some evidences that galectin- 3 interacts with $\beta$-catenin, a molecule involved with $\mathrm{Wnt}$ signaling pathway. Here, we evaluate the role of galectin-3 in tumor growth and metastasis, as well as its interaction with $\beta$-catenin. Murine melanoma cells (B16F10) were injected subcutaneously and intravenously in male C57BL/6 wild-type (WT) and galectin-3 knockout (KO) mice. Tumor growth and lung melanoma colonies were assessed. The expression of galectin-3 and $\beta$-catenin was evaluated by immuno-histochemistry. We observed that tumor growth did not differ between the groups. However, to metastasis, the number of lung colonies in WT mice was significantly increased in comparison to that observed in $\mathrm{KO}$ mice. The cytoplasm expression of galectin- 3 was observed in subcutaneous and metastatic tumors, in both groups. We observed its nuclear expression in some of subcutaneous tumors of KO mice. The expression of $\beta$-catenin was detected in cell membrane of all subcutaneous tumors analyzed, whereas in the metastatic tumors we observed both cytoplasm and cell membrane staining. Altogether, our data suggest that galectin-3 favors the metastasis of melanoma cells and this process is not associated with $\beta$-catenin.
\end{abstract}

Keywords: Melanoma; Galectin-3; Wnt Signaling; $\beta$-Catenin; Metastasis

\section{INTRODUCTION}

Cutaneous melanoma accounts for 4 percent of all skin cancer. However, it is responsible for 80 percent of deaths associated to skin malignancies [1]. Melanocytes are localized to the dermal-epidermal junction and have the capacity to proliferate and form epidermal and dermal aggregates, known as nevi. The malignant transformation of melanocytes consists of multiple, complex processes characterized by changes in the expression of molecules involved in the control of cell growth, proliferation, adhesion and death [2,3]. Several lines of evidence suggest that pathogenesis of melanoma is a multistep process that may include the phases of benign nevi, dysplastic nevi, radial and vertical growth-phase melanoma and metastatic melanoma [4]. In vivo, tumor invasion and the metastatic potential of various human cancers, including melanoma, were associated with the expression of galectin-3 [5-8].

Galectin-3 is a member of the group of lectins that bind $\beta$-galactosides and recognize the $\mathrm{N}$-acetyllactosamine structure of several glycoconjugates [9]. Isolated as a monomer, it has a molecular weight that varies from 29 to $35 \mathrm{kDa}$, depending on the species $[10,11]$. Galectin-3 belongs to the chimera lectin group characterized by one carbohydrate recognition domain (CRD) located at the C-terminal, which consists of $110-130$ amino acids and contains multiple long, homologous repeats rich in proline and glycine. Galectin-3 expression has been reported in monocytes, macrophages, endothelial cells and several epithelial tissues including mammary, colonic and kidney. It plays an important role in tumor cell adhesion, proliferation, differentiation, angiogenesis, and metastasis in several types of tumors [12].

Another interesting protein, $\beta$-catenin, seems to be associated with galectin-3 because of their similar molecular structural and some studies have suggested the possibility of their direct association in cancer progression [13-15]. $\beta$-catenin is a crucial downstream effector com- 
ponent of the Wnt signaling pathway. The Wnt proteins constitute a large family of molecules that control embryogenesis and adult tissue homeostasis [16]. This pathway is evolutionarily conserved and regulates cellular proliferation, morphology, motility, axis formation, and organ development, and it is associated with many human diseases, including cancer $[17,18]$. In the absence of Wnt signaling, GSK3- $\beta$ phosphorylates $\beta$-catenin, targeting it for ubiquitination and degradation. When Wnt signaling is activated, GSK3- $\beta$ is inactivated; the dephosphorylation of $\beta$-catenin leads to its accumulation and translocation into the nucleus, where it binds to the transcriptional factor Tcf/Lef and serves as a co-activator of Tcf/Lef to stimulate the transcription of Wnt target genes involved in cell proliferation $[19,20]$. Like $\beta$-catenin, endogenous galectin-3 is found in the cytoplasm, on the cell surface, and in the nucleus. In the nucleus, it undergoes phosphorylation catalyzed by CK1, which serves as a signaling switch for nuclear export [21].

The aim of this study was to evaluate the role of galectin-3 expression in murine melanoma and its interaction with $\beta$-catenin expression.

\section{MATERIALS AND METHODS}

\subsection{Cell Culture}

The metastatic murine melanoma cell line B16F10 was used for both in vitro and in vivo assays. Cells were routinely cultured in RPMI1640 medium containing 10\% FCS, penicillin and streptomycin (complete medium) and harvested upon $90 \%$ confluence using $0.25 \%$ trypsin and $0.02 \%$ EDTA in PBS.

\subsection{Western Blotting}

B16F10 cells were washed twice in PBS, harvested by cell scraping and lysed with RIPA buffer (10 mM Trischloride, $150 \mathrm{mM} \mathrm{NaCl}, 1 \% \mathrm{NP} 40,0.5 \%$ deoxycholate, $1 \mathrm{mM} \mathrm{MgCl}_{2}$ and $1 \mathrm{mM} \mathrm{CaCl}$ ) containing protease inhibitors $(1 \mathrm{~g} / \mathrm{ml}$ each of leupeptin, pepstatin and aprotinin). After centrifugation for 30 minutes at $4^{\circ} \mathrm{C}$, the supernatant was used as the total cell lysate. Lysate from the Tm1 cell line was used as a negative control for galectin-3 expression in western blots [22]. Protein concentration was estimated using the BCA protein assay kit (BioAgency). Extracts containing $30 \mu \mathrm{g}$ of protein were loaded into each lane of a sodium dodecyl sulfate polyacrylamide gel $(12 \% \mathrm{v} / \mathrm{v})$ under denaturing and reducing conditions. After electrophoresis, proteins were transferred onto a PVDF (polyvinylidene fluoride) membrane (BioRad) by semi-dry blotting. Galectin-3 was immunodetected using a primary rabbit polyclonal antibody (1:1000, Santa Cruz Biotechnology) and a secondary antibody conjugated with AP-alkaline phosphatase, goat anti-rabbit immunoglobulin G (1:1000, Santa Cruz Bio- technology). The bands were visualized by colorimetric methods using NBT (nitroblue tetrazolium chlorideBioRad) and BCIP (5-bromo-4-chloro-3-indolyl-fosfatoBioRad).

\subsection{Indirect Immunofluorescence}

For the immunofluorescence assay, B16F10 cells were seeded onto coverslips and serum-starved overnight. Cells were stimulated with $10 \%$ fetal bovine serum for $60 \mathrm{~min}$ and then fixed and permeabilized with $2 \%$ paraformaldehyde and $0.5 \%$ Triton X-100 in PBS for $10 \mathrm{~min}$. Next, they were incubated with 1:50 galectin-3 polyclonal rabbit antibody (Santa Cruz Biotechnology) for 30 min at room temperature. The secondary antibody conjugated with fluorescein isothiocyanate (FITC) (Jackson Immuno Research) was incubated with the samples for $30 \mathrm{~min}$ at room temperature. Fluorescence staining was visualized with Zeiss confocal fluorescent microscope (Axiovert $100 \mathrm{M}$ ), and photos were taken with a camera using LSM510 Meta imaging software.

\subsection{In Vivo Assay}

Galectin-3-deficient animals, generated from C57BL/6 mice by producing a targeted disruption of the galectin-3 gene in mouse embryonic stem cells, as previously reported. Homozygous mice were viable and fertile; when compared with galectin-3 expressing mice. Exhibited comparable reproductive capacities and exhibited similar characteristics in terms of blood chemistries, peripheral blood leukocyte and erythrocyte counts, lymphocyte subpopulations, and histological analyses of organs and tissues [23].

Tumors were induced by inoculating melanoma cells subcutaneously (s.c) $\left(1 \times 10^{6}\right.$ cells/ animal $)$ in groin region of five male C57/BL6 and five galectin-3 knock-out mice, both at approximately 7 weeks of age. Tumor growth was measured three times per week after the tumors were detected by palpation. Tumor volume was calculated according to the formula: $\mathrm{V}=\mathrm{L} \times \mathrm{W} 2 \times \pi / 6$, where $\mathrm{L}$ is the length and $\mathrm{W}$ is width of the tumor mass [24]. Mice were sacrificed 21 days after injection; fragments of tumor were collected and fixed in $10 \%$ phosphate-buffered formalin.

For the experimental metastasis assay, $1 \times 10^{6}$ melanoma cells were injected intravenously (i.v.) in lateral tail vein of five male C57/BL6 and five galectin-3 knockout mice with approximately 7 weeks of age. After 21 days, the lungs were excised, and melanoma colonies present on their surface were counted. The lungs were then fixed in $10 \%$ phosphate-buffered formalin and embedded in paraffin.

Research Ethics Committee/ Hospital São Paulo: CEP $1521 / 06$. 


\subsection{Immunohistochemistry}

Slides of $5-\mu \mathrm{m}$ sections were obtained from tumor blocks containing local and metastatic animal tumors. Tissue sections were deparaffinized, rehydrated, and placed in a pressure cooker with citrate buffer, $\mathrm{pH} 6.0$, for $5 \mathrm{~min}$ after reaching boiling temperature to retrieve antigenic sites masked by formalin fixation. The tissue sections were then placed in 3\% hydrogen peroxide for $5 \mathrm{~min}$ to inactivate endogenous peroxidases, blocked for $20 \mathrm{~min}$ with normal horse serum (Vectastain Elite ABC Kit; Vector Laboratories, Burlingame, CA), and subsequently incubated overnight at $4^{\circ} \mathrm{C}$ with $1: 100$ galectin-3 polyclonal rabbit antibody (Santa Cruz Biotechnology) or 1:100 $\beta$-catenin monoclonal mouse antibody (Santa Cruz Biotechnology). The sections were then treated with biotinylated secondary antibody (Universal LSAB2 Kit; DakoCytomation) for $10 \mathrm{~min}$, followed by a $10 \mathrm{~min}$ incubation with streptavidin-horseradish peroxidase and 3,3diaminobenzidine solution for another $5 \mathrm{~min}$ at room temperature. Counterstaining was performed with $10 \%$ hematoxylin. Staining was scored according to staining intensity, as described previously $[25,26]$. The intensity scoring system was as follows: 0 , no immunoreactivity; 1 , weak staining; 2, intermediate staining; and 3, strong staining.

\subsection{Statistical Analysis}

$\mathrm{T}$ All values are expressed as mean plus/minus standard deviation (SD). Data were analyzed by the Mann-Whitney test, and $\mathrm{p}$ values $<0.05$ were considered statistically significant.

\section{RESULTS}

\subsection{Galectin-3 Detection in B16F10}

First of all, by western blotting test we analyzed the expression of galectin-3 in total protein extract obtained from lysates of B16F10 cells and Tm1 cells (negative control). We verified that galectin-3 was highly expressed in murine melanoma line (B16F10 cells, Figure 1(a)) and this expression was observed in the cytoplasm of melanoma cells, by immunofluorescence (Figure 1(b)).

\subsection{Tumor Growth Pattern}

Melanoma cells were injected into the subcutaneous tissue of galectin-3 knock-out and wild-type mice. Tumor growth was monitored for 21 days. Palpable tumors became detectable on the 8 th day after cell injection in $40 \%$ of the wild-type mice. On the 18th day, all animals in this group presented tumors. In the knock-out animals, a palpable tumor was identified in one mouse 11 days after inoculation. On the 13th day, all animals in this group

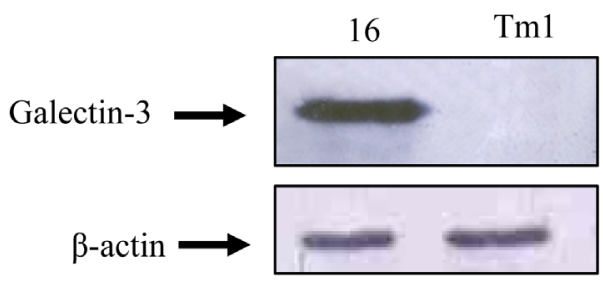

(a)

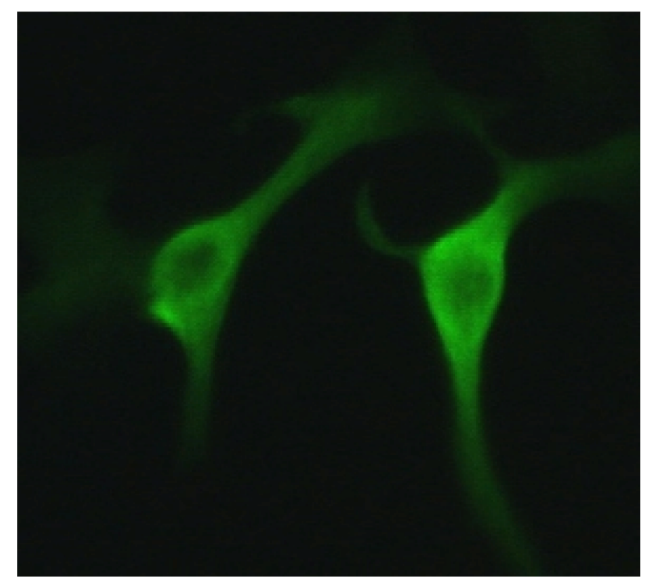

(b)

Figure 1. Melanoma cell line B16F10 expresses galectin-3. Total protein extract of B16F10 and Tm1 cells were used by western blotting (a) to confirm the expression of galetin-3 in B16F10 cells; (b) Photomicrograph of indirect immuno-fluorescence showed that the expression of galectin-3 in B16F10 cells was cytoplasmatic.

presented tumors (Figure 2(a)). However, there was not a statistical difference in tumor growth between the groups ( $\mathrm{p}=0.2282)$ (Figure 2(b)).

We analyzed the expression of galectin- 3 and $\beta$-catenin by immunohistochemistry. In relation to galectin-3, the results showed cytoplasmic expression in all subcutaneous tumors. The intensity of the stain was predominantly weak in tumors obtained from wild-type group and was intermediate in knock-out group. Furthermore, $50 \%$ of the knock-out animals also expressed galectin-3 in cell nuclei (Table 1 and Figure 3). To $\beta$-catenin, we verified strong expression in membrane cell of subcutaneous tumor in both groups analyzed (Table 1 and Figure 3).

\subsection{Metastasis Assay}

For the metastasis assay, melanoma cells were injected intravenously (i.v.) into groups of galectin-3 knock-out and wild-type mice and the number of lung colonies were counted after 21 days. The lungs of the wild-type animals presented a large number of metastatic colonies when compared to the knock-out animals. We observed $27.3 \pm 5.4$ and $4.0 \pm 3.9$ colonies in the wild-type and knock-out groups, respectively (Figure 4) and this dif- 
ference was statistically significant $(\mathrm{p}<0.014)$.

As in the subcutaneous tumors, we evaluated the expression of proteins galectin-3 and $\beta$-catenin by immunohistochemistry in metastatic tumors. To galectin-3, we detected cytoplasmatic expression in tumor cells from both groups, and the intensity of staining varied between intermediate and strong. Only one animal from the wild-type group also presented nuclear expression (Ta-

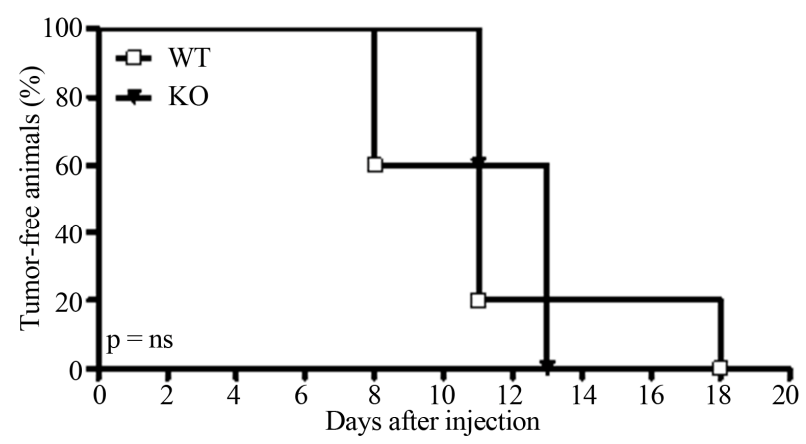

(a)

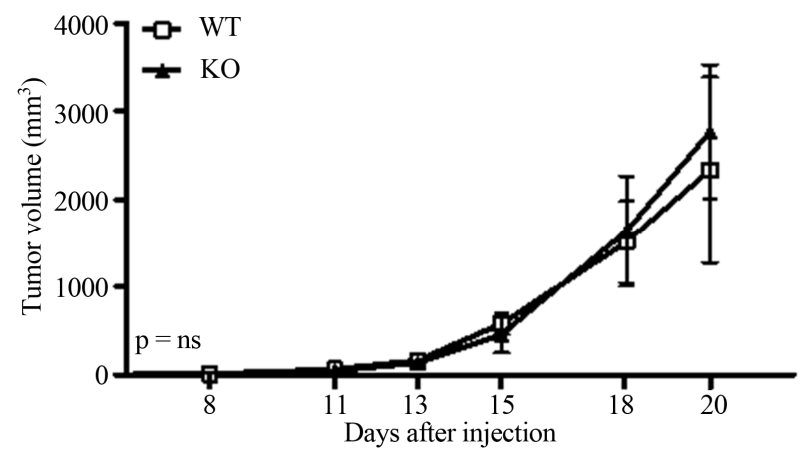

(b)

Figure 2. Tumor growth did not differ in subcutaneous tissue. C57B1/6 wild-type and galectin-3 knock-out mice were subcutaneously injected with $106 \mathrm{~B} 16 \mathrm{~F} 10$ viable melanoma cells. No statistical significance was observed $(\mathrm{p}>0.05)$ to tumor detection analysis (a) or to tumor growth analysis (b). ble 2 and Figure 3). However, the expression of $\beta$-catenin was weak in the cytoplasm and membrane cell in all animals from both groups (Table 2 and Figure 3).

\section{DISCUSSION}

In recent years, studies have attempted to elucidate the epidemiological, clinical and molecular aspects of tumors $[3,6]$. Many proteins seem to be involved in neoplastic mechanisms. One such protein is galectin-3, a lectin protein that is characterized by the presence of carbohydrate recognition domains (CRD) that permit interaction with sugar molecules and play an important role in cellular growth, proliferation, adhesion and death. In melanomas, galectin-3 has been identified as an important molecule in tumor growth and metastasis. Moreover, this protein has been linked to Wnt signaling pathway as a $\beta$ catenin binding partner $[27,28]$. Here, we have demonstrated the involvement of galectin-3 in murine melanoma growth and metastases.

We observed prominent expression of galectin-3 in B16F10 cells, a finding that has also been described in other studies dealing with human and murine melanoma cell lines [29,30]. A similar result has previously indicated that the overexpression of galectin-3 may confer a selective survival advantage and a resistance to apoptosis in human breast carcinoma cell lines by specifically in-

Table 1. Subcutaneous tumor expression of galectin-3 and $\beta$ catenin in WT and KO mice by immunohistochemistry.

\begin{tabular}{cccccc}
\hline \multirow{2}{*}{ Groups } & \multicolumn{2}{c}{ GALECTIN-3 $(\mathrm{n}=5)$} & \multicolumn{2}{c}{ B-CATENIN $(\mathrm{n}=4)^{*}$} \\
\cline { 2 - 6 } & \multicolumn{2}{c}{ Cytoplasm } & Nucleus & \multicolumn{2}{c}{ Membrane } \\
\cline { 2 - 6 } & Weak & Intermediate & Weak & Intermediate & Strong \\
\hline WT & $80 \%$ & $20 \%$ & $0 \%$ & $0 \%$ & $100 \%$ \\
KO & $0 \%$ & $100 \%$ & $50 \%$ & $25 \%$ & $75 \%$ \\
\hline
\end{tabular}

*death of an animal at 21 days after inoculation.

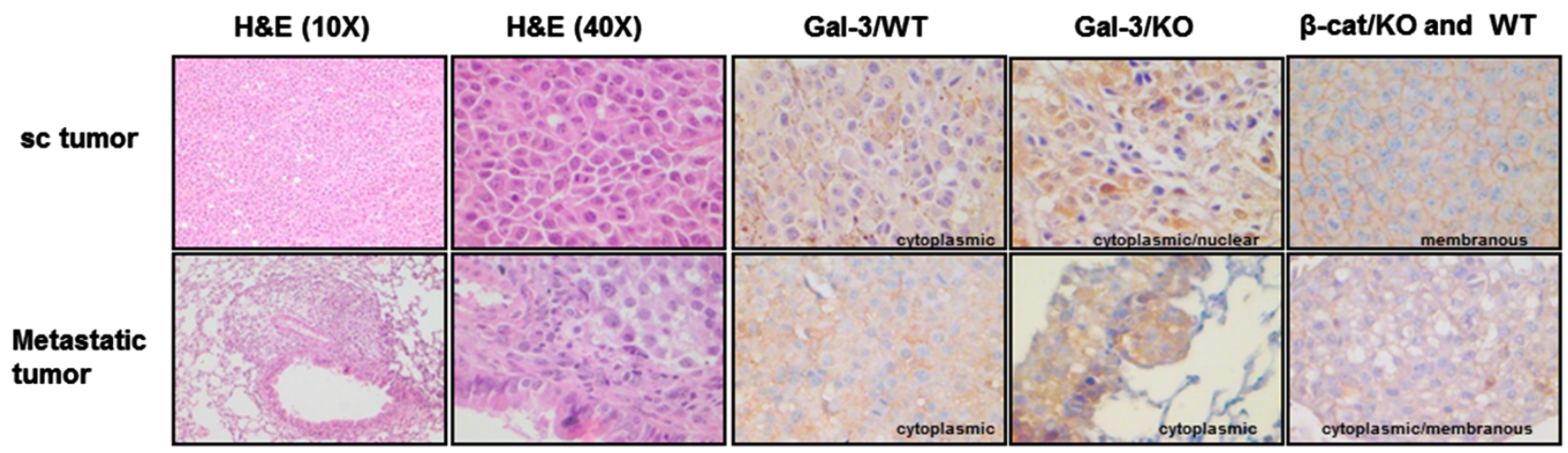

Figure 3. Photomicrographs of galectin-3 and $\beta$-catenin expression in situ. Subcutaneous (sc) and metastatic lung tissues from C57Bl/6 wild-type and galectin-3 knock-out mice injected with B16F10 viable melanoma cells were used to analysis of galectin-3 and $\beta$-catenin expression by histological (H\&E staining) and immunohistochemistry analysis. In subcutaneous tumors or lung metastasis colonies the expression of galectin- 3 expression was cytoplasmic in all animals of both groups. To $\beta$-catenin, membrane cell and cytoplasmatic expression was observed in subcutaneous and lung tumors in all animals of both groups. 
Table 2. Metastatic lung tumor expression of galectin-3 and $\beta$-catenin in WT and KO mice by immunohistochemistry.

\begin{tabular}{|c|c|c|c|c|c|c|c|}
\hline \multirow{3}{*}{ Groups } & \multicolumn{3}{|c|}{ GALECTIN-3 $(\mathrm{n}=4)^{*}$} & \multicolumn{4}{|c|}{ B-CATENIN $(\mathrm{n}=5)$} \\
\hline & \multicolumn{2}{|c|}{ Cytoplasm } & \multicolumn{2}{|l|}{ Nucleus } & \multicolumn{2}{|l|}{ Cytoplasm } & Membrane \\
\hline & Intermediate & Strong & Weak & Weak & Weak Intermediate & Weak & Weak Intermediate \\
\hline WT & $25 \%$ & $75 \%$ & $25 \%$ & $50 \%$ & $50 \%$ & $50 \%$ & $50 \%$ \\
\hline $\mathrm{KO}$ & $75 \%$ & $25 \%$ & $0 \%$ & $100 \%$ & $0 \%$ & $100 \%$ & $0 \%$ \\
\hline
\end{tabular}

*death of an animal at second day after inoculation.

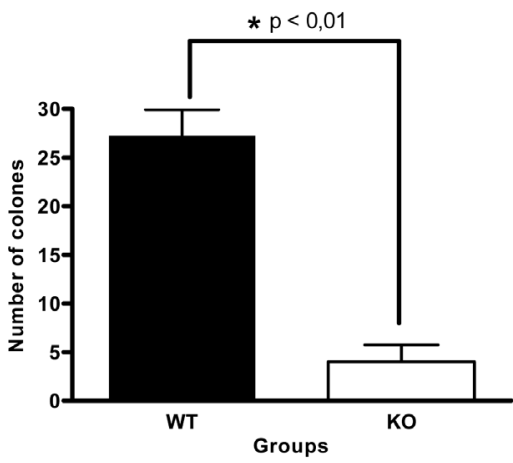

(a)

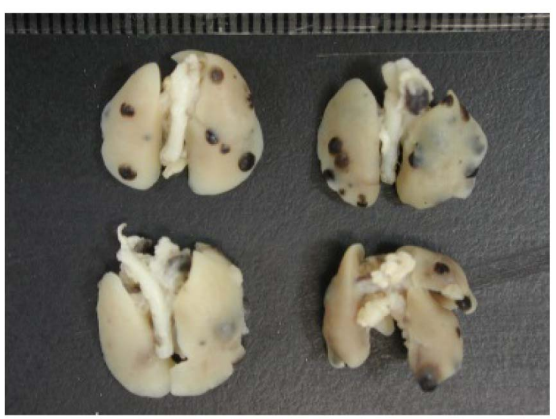

WT

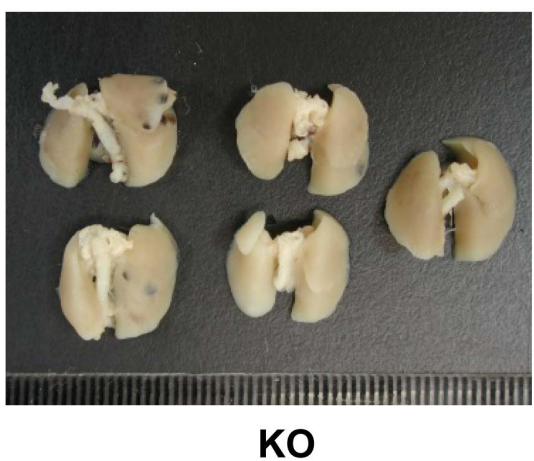

(b)

Figure 4. Galectin-3 knock-out mice show reduced lung metastasis process. C57B1/6 wild-type (WT) and galectin-3 knock-out (KO) mice were intravenously injected with B16F10 viable melanoma cells and 21 days after the injection the lung were excised and analyzed to metastasis process. The number of metastasis colonies in galectin-3 knock-out mice showed statistical significant reduction in comparison to observed in wild-type mice (a); Representative image of lung metastasis colonies in animals of both groups (b).

fluencing cell adhesion to the extracellular matrix during invasion and metastasis [8].

The induction of murine subcutaneous melanoma had been extensively documented as an important experimental model for the investigation of tumor progression $[31,32]$. Our study demonstrated that in wild-type mice that express galectin-3, the tumor mass appeared eight days after cell injection, as previously described [33,34]. However, galectin-3 knock-out animals presented a three-day delay before the detection of palpable subcutaneous tumors. In fact, we know that tumor cell inoculation generates an inflammatory response and this inflammatory microenvironment seems to be essential for tumor implantation, because inflammation leads to high levels of several distinct cytokines, chemokines and growth factors produced by inflammatory cells [35]. Furthermore, several studies describe an important function to galectin-3 in inflammatory cell resistance to apoptosis. Hsu et al. (2000) found that peritoneal macrophages from galectin-3 knock-out mice were more prone to undergoing apoptosis than those from wild-type mice when treated with apoptotic stimuli, suggesting that expression of galectin-3 in peritoneal cavity inflammatory cells may lead to longer cell survival, thus prolonging inflammation [23]. These results strongly support the concept that galectin-3 is a positive regulator of inflammatory responses.
Interestingly, on the 18th day of tumor development, the subcutaneous tumors from galectin-3 knock-out mice reached a larger size than those from wild-type mice. Nevertheless, until that time, tumor growth had been similar in both groups of animals analyzed. Taken together, our results indicate biphasic melanoma behavior: first, there is a period characterized by independence of the presence of galectin-3 in the tumor microenvironment, followed by a second phase in which the absence of galectin-3 enhanced tumor growth.

Conflicting results have been reported regarding galectin-3 in tumor pathophysiology. Its expression may vary from one tissue or tumor to another and the difference in the pattern of expression seems to determine tumor evolution. In our study, galectin-3 exhibited cytoplasmic expression in all wild-type subcutaneous melanomas. Thick tumors exhibited weak intensity, whereas thin tumors manifested intermediate staining intensity. The same finding was observed in a study using a melanoma cell line in a mouse experimental model [30]. However, in half of the knock-out animals, galectin-3 expression was observed in both cytoplasm and nucleus. In addition, these animals presented smaller tumors. Pietro et al. 2006 have shown that melanocytes accumulate galectin3 during tumor progression, particularly in the nucleus [6]. The same event has been reported in the literature, 
where nuclear galectin-3 expression is related to apoptotic sensitivity as compared to cells in which the protein expression is exclusively cytoplasmic. At this point, it is relevant to emphasize that many studies have associated other tumors with this galectin-3 expression pattern [36, 37]. Therefore, we postulate that nuclear galectin- 3 might act as an inhibitory factor for tumor growth in knock-out mice.

Although there is evidence of a possible interaction between galectin- 3 and $\beta$-catenin in some tumors, we did not observe a correlation between the expression patterns of these proteins in subcutaneous melanoma in the present study.

In terms of metastasis, the wild-type animals presented significantly more pulmonary colonies than the knockout animals. These results suggest that this protein may contribute to melanoma cell implantation in the lung, considering its presence in the normal pulmonary epithelium, as recently reported by Kim et al. [28]. Therefore, galectin-3 at the organ endothelium seems to serve as the first anchor for circulating cancer cells and can facilitate organ-specific metastasis during this complex biological process [29]. We observed cytoplasmic expression of galectin-3 in melanoma metastases in all animals, and the staining was more intense than that observed in subcutaneous tumors. These findings are supported by a study that compared melanoma primary tumors and metastasis [6]. $\beta$-catenin expression was present in the cytoplasm and membrane cell in both animal groups, confirming its important role in melanoma cell adhesion [27]. The cytoplasmic presence of $\beta$-catenin has been attributed with a protective role in the early stages of melanoma development $[38,39]$. In metastatic melanoma, the presence of this protein in the cytoplasm suggests the possible activation of the Wnt signaling pathway in this model. Although, we did not find $\beta$-catenin in cell nucleus, its translocation to this compartment is known to be preceded by the accumulation of its hypophosphorylated form in the cytoplasm. Therefore, our results seem to reflect this crucial phase that prepares the cell to initiate Wnt signaling upon melanoma progression. Some studies have indicated a relationship between galectin-3 and Wnt/ catenin, such as a recent report demonstrating that galectin-3 expression in the cytoplasm and nucleus of welldifferentiated thyroid neoplasms seems to be associated with the activation of the Wnt signaling pathway, suggesting a role for galectin-3 in thyroid carcinogenesis [30].

In conclusion, our data suggest that galectin-3 favors the melanoma metastasis process and this effect is not associated to its interaction with $\beta$-catenin.

\section{ACKNOWLEDGEMENTS}

Our thanks go to Professor Célia Regina Whitaker Carneiro from De- partment of Micro and Immunology of Federal Universidade de São Paulo, Brazil for kindly provided the B16F10 cells and Professor Miriam Galvonas Jasiuliuonis from Department of Pharmacology of Federal Universidade of São Paulo, Brazil for kindly provided the Tm1 cells and Professor FU-Tong Liu for kindly provided the galectin-3 knock-out mice.

\section{REFERENCES}

[1] Tucker, M.A. and Goldstein, A.M. (2003) Melanoma etiology: Where are we? Oncogene, 22, 3042-3052. http://dx.doi.org/10.1038/sj.onc. 1206444

[2] Chambers, A.F., Groom, A.C. and MacDonald, I.C. (2002) Dissemination and growth of cancer cells in metastatic sites. Nature Reviews Cancer, 2, 563-572. http://dx.doi.org/10.1038/nrc865

[3] Gaggioli, C. and Sahai, E. (2007) Melanoma invasionCurrent knowledge and future directions. Pigment Cell Research, 20, 161-172. http://dx.doi.org/10.1111/j.1600-0749.2007.00378.x

[4] Clark, W.H., Elder, D.E., Guerry, D., Epstein, M.N., Greene, M.H. and Van Horn, M. (1984) A study of tumor progression: the precursor lesions of superficial spreading and nodular melanoma. Human Pathology, 15, 11471165. http://dx.doi.org/10.1016/S0046-8177(84)80310-X

[5] Song, Y.K., Billiar, T.R. and Lee, Y.J. (2002) Role of galectin-3 in breast cancer metastasis: Involvement of nitric oxide. American Journal of Pathology, 160, 1069-1075. http://dx.doi.org/10.1016/S0002-9440(10)64927-9

[6] Prieto, V.G., Mourad-Zeidan, A.A., Melnikova, V., Johnson, M.M., Lopez, A., Diwan, A.H., et al. (2006) Galectin-3 expression is associated with tumor progression and pattern of sun exposure in melanoma. Clinical Cancer Research, 12, 6709-6715.

http://dx.doi.org/10.1158/1078-0432.CCR-06-0758

[7] Takenaka, Y., Inohara, H., Yoshii, T., Oshima, K., Nakahara, S., Akahani, S., et al. (2003) Malignant transformation of thyroid follicular cells by galectin-3. Cancer Letters, 195, 111-119.

http://dx.doi.org/10.1016/S0304-3835(03)00056-9

[8] Tsuboi, K., Shimura, T., Masuda, N., Ide, M., Tsutsumi, S., Yamaguchi, S., et al. (2007) Galectin-3 expression in colorectal cancer: Relation to invasion and metastasis. Anticancer Research, 27, 2289-2296.

[9] Barondes, S.H., Castronovo, V., Cooper, D.N., Cummings, R.D., Drickamer, K., Feizi, T., et al. (1994) Galectins: A family of animal beta-galactoside-binding lectins. Cell, 76, 597-598. http://dx.doi.org/10.1016/0092-8674(94)90498-7

[10] Barondes, S.H., Cooper, D.N., Gitt, M.A. and Leffler, H.G. (1994) Structure and function of a large family of animal lectins. The Journal of Biological Chemistry, 269, 2080720810.

[11] Dumic, J., Dabelic, S. and Flögel, M. (2006) Galectin-3: An open-ended story. Biochim Biophys Acta, 1760, 616635. http://dx.doi.org/10.1016/j.bbagen.2005.12.020

[12] Liu, F.T. and Rabinovich, G.A. (2005) Galectins as mo- 
dulators of tumour progression. Nature Reviews Cancer, 5, 29-41. http://dx.doi.org/10.1038/nrc1527

[13] Shimura, T., Takenaka, Y., Fukumori, T., Tsutsumi, S., Okada, K., Hogan, V., et al. (2005) Implication of galectin-3 in Wnt signaling. Cancer Research, 65, 3535-3537. http://dx.doi.org/10.1158/0008-5472.CAN-05-0104

[14] Shimura, T., Takenaka, Y., Tsutsumi, S., Hogan, V., Kikuchi, A. and Raz, A. (2004) Galectin-3, a novel binding partner of beta-catenin. Cancer Research, 64, 6363-6367. http://dx.doi.org/10.1158/0008-5472.CAN-04-1816

[15] Weinberger, P.M., Adam, B.L., Gourin, C.G., Moretz, W.H., Bollag, R.J., Wang, B.Y., et al. (2007) Association of nuclear, cytoplasmic expression of galectin-3 with beta-catenin/Wnt-pathway activation in thyroid carcinoma. Archives of Otolaryngology-Head and Neck Surgery, 133, 503-510. http://dx.doi.org/10.1001/archotol.133.5.503

[16] Klingensmith, J. and Nusse, R. (1994) Signaling by wingless in Drosophila. Developmental Biology, 166, 396-414. http://dx.doi.org/10.1006/dbio.1994.1325

[17] Zhurinsky, J., Shtutman, M. and Ben-Ze'ev, A. (2000) Plakoglobin and beta-catenin: Protein interactions, regulation and biological roles. Journal of Cell Science, 113, 3127-3139.

[18] Zimmerman, Z.F., Kulikauskas, R.M., Bomsztyk, K., Moon, R.T. and Chien, A.J. (2013) Activation of Wnt/ $\beta$-catenin signaling increases apoptosis in melanoma cells treated with trail. PLoS One, 8, e69593. http://dx.doi.org/10.1371/journal.pone.0069593

[19] Huang, H. and He, X. (2008) Wnt/beta-catenin signaling: New (and old) players and new insights. Current Opinion in Cell Biology, 20, 119-125.

http://dx.doi.org/10.1016/j.ceb.2008.01.009

[20] Ikeda, S., Kishida, S., Yamamoto, H., Murai, H., Koyama, S. and Kikuchi, A. (1998) Axin, a negative regulator of the Wnt signaling pathway, forms a complex with GSK3beta and beta-catenin and promotes GSK-3beta-dependent phosphorylation of beta-catenin. EMBO Journal, 17, 1371-1384. http://dx.doi.org/10.1093/emboj/17.5.1371

[21] Takenaka, Y., Fukumori, T., Yoshii, T., Oka, N., Inohara, H., Kim, H.R., et al. (2004) Nuclear export of phosphorylated galectin-3 regulates its antiapoptotic activity in response to chemotherapeutic drugs. Molecular and Cellular Biology, 24, 4395-4406. http://dx.doi.org/10.1128/MCB.24.10.4395-4406.2004

[22] Correa, M., Machado, J., Carneiro, C.R., Pesquero, J.B., Bader, M., Travassos, L.R., et al. (2005) Transient inflammatory response induced by apoptotic cells is an important mediator of melanoma cell engraftment and growth. International Journal of Cancer, 114, 356-363. http://dx.doi.org/10.1002/ijc.20673

[23] Hsu, D.K., Yang, R.Y., Pan, Z., Yu, L., Salomon, D.R., Fung-Leung, W.P., et al. (2000) Targeted disruption of the galectin-3 gene results in attenuated peritoneal inflammatory responses. American Journal of Pathology, 156, 1073-1083. http://dx.doi.org/10.1016/S0002-9440(10)64975-9

[24] Tomayko, M.M. and Reynolds, C.P. (1989) Determination of subcutaneous tumor size in athymic (nude) mice.
Cancer Chemother Pharmacology, 24, 148-154. http://dx.doi.org/10.1007/BF00300234

[25] Seidal, T., Balaton, A.J. and Battifora, H. (2001) Interpretation and quantification of immunostains. The American Journal of Surgical Pathology, 25, 1204-1207. http://dx.doi.org/10.1097/00000478-200109000-00013

[26] Wick, M.R. and Mills, S.E. (2001) Consensual interpretive guidelines for diagnostic immunohistochemistry. The American Journal of Surgical Pathology, 25, 1208-1210. http://dx.doi.org/10.1097/00000478-200109000-00014

[27] Bonitsis, N., Batistatou, A., Karantima, S. and Charalabopoulos, K. (2006) The role of cadherin/catenin complex in malignant melanoma. Experimental Oncology, 28, 187193.

[28] Kim, H., Lee, J., Hyun, J.W., Park, J.W., Joo, H.G. and Shin, T. (2007) Expression and immunohistochemical localization of galectin-3 in various mouse tissues. Cell Biology International, 31, 655-662. http://dx.doi.org/10.1016/j.cellbi.2006.11.036

[29] Krishnan, V., Bane, S.M., Kawle, P.D., Naresh, K.N. and Kalraiya, R.D. (2005) Altered melanoma cell surface glycosylation mediates organ specific adhesion and metastasis via lectin receptors on the lung vascular endothelium. Clinical \& Experimental Metastasis, 22, 11-24. http://dx.doi.org/10.1007/s10585-005-2036-2

[30] Vereecken, P., Debray, C., Petein, M., Awada, A., Lalmand, M.C., Laporte, M., et al. (2005) Expression of galectin-3 in primary and metastatic melanoma: immunohistochemical studies on human lesions and nude mice xenograft tumors. Archives of Dermatological Research, 296, 353358. http://dx.doi.org/10.1007/s00403-004-0536-6

[31] Harhaji, L., Mijatović, S., Maksimović-Ivanić, D., Stojanović, I., Momcilović, M., Maksimović, V., et al. (2008) Anti-tumor effect of Coriolus versicolor methanol extract against mouse B16 melanoma cells: In vitro and in vivo study. Food and Chemical Toxicology, 46, 1825-1833. http://dx.doi.org/10.1016/j.fct.2008.01.027

[32] Wong, R.P., Ng, P., Dedhar, S. and Li, G. (2007) The role of integrin-linked kinase in melanoma cell migration, invasion, and tumor growth. Molecular Cancer Therapeutics, 6, 1692-1700. http://dx.doi.org/10.1158/1535-7163.MCT-07-0134

[33] Dietrich, A., Stockmar, C., Aust, G., Endesfelder, S., Guetz, A., Sack, U., et al. (2006) Intraoperative subcutaneous or intrasplenic vaccination with modified autologous tumor cells leads to enhanced survival in a mouse tumor model. Journal of Cancer Research and Clinical Oncology, 132, 379-388. http://dx.doi.org/10.1007/s00432-005-0073-5

[34] Mansour, M., Pohajdak, B., Kast, W.M., Fuentes-Ortega, A., Korets-Smith, E., Weir, G.M., et al. (2007) Therapy of established B16-F10 melanoma tumors by a single vaccination of CTL/T helper peptides in VacciMax. Journal of Translational Medicine, 5, 20. http://dx.doi.org/10.1186/1479-5876-5-20

[35] Coussens, L.M. and Werb, Z. (2002) Inflammation and cancer. Nature, 420, 860-867. http://dx.doi.org/10.1038/nature01322

[36] Califice, S., Castronovo, V., Bracke, M. and van den Brûle, 
F. (2004) Dual activities of galectin-3 in human prostate cancer: Tumor suppression of nuclear galectin-3 vs tumor promotion of cytoplasmic galectin-3. Oncogene, 23, 75277536. http://dx.doi.org/10.1038/sj.onc. 1207997

[37] Honjo, Y., Inohara, H., Akahani, S., Yoshii, T., Takenaka, Y., Yoshida, J., et al. (2000) Expression of cytoplasmic galectin-3 as a prognostic marker in tongue carcinoma. Clinical Cancer Research, 6, 4635-4640.

[38] Bachmann, I.M., Straume, O., Puntervoll, H.E., Kalvenes, M.B. and Akslen, L.A. (2005) Importance of P-cadherin, beta-catenin, and Wnt5a/frizzled for progression of melanocytic tumors and prognosis in cutaneous melanoma. Clinical Cancer Research, 11, 8606-8614. http://dx.doi.org/10.1158/1078-0432.CCR-05-0011

[39] Maelandsmo, G.M., Holm, R., Nesland, J.M., Fodstad, Ø. and Flørenes, V.A. (2003) Reduced beta-catenin expression in the cytoplasm of advanced-stage superficial spreading malignant melanoma. Clinical Cancer Research, 9, 3383-3388. 